ECCOMAS Proceedia
COMPDYN 2021

$8^{\text {th }}$ ECCOMAS Thematic Conference on Computational Methods in Structural Dynamics and Earthquake Engineering M. Papadrakakis, M. Fragiadakis (eds.)

\title{
OPTIMIZATION OF STEEL-JACKETING RETROFITTING OF SHEAR-CRITICAL AND DUCTILITY CRITICAL RC FRAME STRUCTURES BY A NOVEL GENETIC ALGORITHM FRAMEWORK
}

\author{
Antonio P. Sberna ${ }^{1}$, Fabio Di Trapani ${ }^{1}$, and Giuseppe C. Marano ${ }^{1}$ \\ ${ }^{1}$ Politecnico di Torino. Dipartimento di Ingegneria Strutturale, Edile e Geotecnica \\ Corso Duca degli Abruzzi 24, 10129, Turin, Italy \\ e-mail: \{antonio.sberna, fabio.ditrapani, giuseppe.marano\}@polito.it
}

\begin{abstract}
The paper presents a new specific optimization framework that is directed at minimizing seismic retrofitting intervention costs of reinforced concrete $(R C)$ frame structures. A genetic algorithm routine is developed to provide as outputs the individuation of the retrofitted columns (topological optimization) and amount of steel-jacketing reinforcement. The major novelty regards the framework's capacity to perform retrofitting optimization both for $R C$ structures with ductility-critical and shear-critical RC columns, also considering the additional shear demand due to infill-frame interaction. Modified genetic operators (population generator, elitism, and mutation) are defined and calibrated to be effective and computationally sustainable. The feasibility of each tentative solution is controlled by a static pushover analysis in the framework of the N2 method, accomplished by a 3D fiber-section model implemented in OpenSees. It is shown that the proposed procedure is sufficiently general and robust to handle structural configurations having different structural deficiencies, significantly reducing invasiveness, downtime, and costs.
\end{abstract}

Keywords: genetic algorithm, structural optimization, seismic retrofitting, existing structures

ISSN:2623-3347 @ 2021 The Authors. Published by Eccomas Proceedia.

Peer-review under responsibility of the organizing committee of COMPDYN 2021.

doi:10.7712/120121.8566.19534 


\section{INTRODUCTION}

Steel-jacketing (SJ) is one of the extensively used technique for retrofitting existing reinforced concrete (RC) structure designed prior to the entry into force of seismic guidelines. The arrangement of a cage made of steel angles and battens provides additional confinement and transverse reinforcement to the $\mathrm{RC}$ elements, also increasing the shear strength.

Even though steel-jacketing is quite effective as a seismic retrofitting technique, its application is invasive because it also involves several related operations, including the demolition and reconstruction of column-side masonries and plasters. This significantly affects the costs and the downtime associated with the intervention.

In this context, one of the major issues that structural engineers face in the design of this kind of interventions regard the determination of the optimal position and arrangement of the retrofitting system. Nowadays the design of this kind of interventions is mainly based on engineer's intuition and experience that needs several trial-and-error attempts, requiring noticeable time consumption.

In the last years, the scientific interest on the structural optimization was mainly focused on sizing and shape optimization of new structures. On the contrary, the issue of the optimization of seismic retrofitting of existing structures has not been investigated many times in the past, while noticeable interest is emerging in the last years. Available studies have been addressed to the optimization of carbon fibre reinforcement of concrete slabs (Chaves and Cuhna 2014 [1]) or FRP jackets (Chisari and Bedon 2016 [2], Seo et al. 2018 [3]). Other applications of seismic engineering optimization are related to fluid viscous dampers (Pollini et al. 2017 [4]), dissipative bracings (Braga et al. 2019 [5]) or both (Lavan and Dargush 2009 [6]) as seismic retrofitting devices for frame buildings.

More recent studies addressed the issue of pushover-based optimization of seismic retrofitting. Among these, Falcone et al. 2019 [7] proposed a framework implementing the optimization of FRP jacketing and steel X-bracings as possible reinforcements for existing $\mathrm{RC}$ structures. Papavasileiou et al. 2020 [8] faced seismic retrofit optimization of encased steelconcrete composite columns comparing three different retrofitting methods: concrete jacketing, steel jacketing and steel bracing.

Regarding steel-jacketing of standard RC columns, a recent study by Di Trapani et al. 2020 [9] proposed an innovative framework aimed at minimizing seismic retrofitting costs through genetic algorithm optimization. The framework provided both the optimization of the position of the reinforced columns and the amount of reinforcement for RC structures presenting ductility deficiencies as major vulnerability, while having adequate capacity against local shear failures. The current paper provides a significant step forward to the methodology proposed by Di Trapani et al. 2020 [9].

An updated optimization framework with general validity is proposed and tested. Besides the ductility issues, the new optimization framework can deal with steel-jacketing optimization of potentially shear-critical RC columns, including also shear-induced mechanisms due to frame-infill interaction. The optimization is carried with a genetic algorithm-based algorithm. Novel genetic operators (population generator, elitism, and mutation) are defined by modifying the standard MATLAB ${ }^{\circledR}$ GA tool. The optimization framework provides as output the cheapest seismic retrofitting intervention among the feasible ones, defining the optimal configuration of the steel jacketing reinforcement of columns in terms of reinforcement location (topological optimization) and spacing between steel battens (sizing optimization). The feasibility of each solution is verified by the results of static pushover analyses in the framework of the N2 method from the results carried out a 3D fibre-section model, developed in the OpenSees software (McKenna et al. 2000 [10]). 


\section{DESIGN OPTIMIZATION FRAMEWORK}

\subsection{Problem statement and general operating principles}

The proposed optimization framework works by connecting the MATLAB® genetic algorithm (GA) tool with a FE structural model developed with the OpenSees software platform. The framework aims at minimizing an objective function that computes the steel-jacketing retrofitting costs as a function of the design variables which define the retrofitting arrangement. These are the position of the retrofitted columns (topological optimization) and the battens spacing (sizing optimization). The feasibility of each tentative solution is assessed by evaluating the ductility capacity and demand ratio $\left(\xi_{\mu}=\mu_{c} / \mu_{d}\right)$ after performing pushover analysis of the structure in the framework of N2 method (Fajfar 2000 [11]). An adaptive penalty function applied in the cases of unfeasible solutions.

The overall structure of the framework reflects the one proposed by Di Trapani et al. 2020 [9], for the optimization of the steel-jacketing retrofitting in case of structures with flexural ductility-related lacks. However, a strong review of the algorithm has been provided to redefine the genetic operators to generalize the framework for both flexural ductility-critical and shear-critical RC structures. The reason behind the need to update the framework is that, differently from RC structures with flexural ductility lacks, for shear-critical structures, a significant number of columns may need to be retrofitted. This is typical when the base shear demand exceeds the shear capacity of a storey. If the number of columns needing retrofitting is a high percentage of those included in the design space, a standard random selection of the individuals defining the population may have reduced probability to find feasible solutions. This condition may lead a GA to stall or to find a local minimum solution even in the unfeasible space (Fig. 1). The first remedy that could be thought to avoid this drawback is the expansion of the population of individuals $(P)$ belonging to the design space to have a major chance to include feasible individuals. However, increasing the individuals means increasing the number on nonlinear static analyses and this very easily brings to a huge computational effort. Therefore, keeping a reduced population and a possibly restricted design space is fundamental to get an effective and affordable optimization through a genetic algorithm associated with to nonlinear structural analyses.
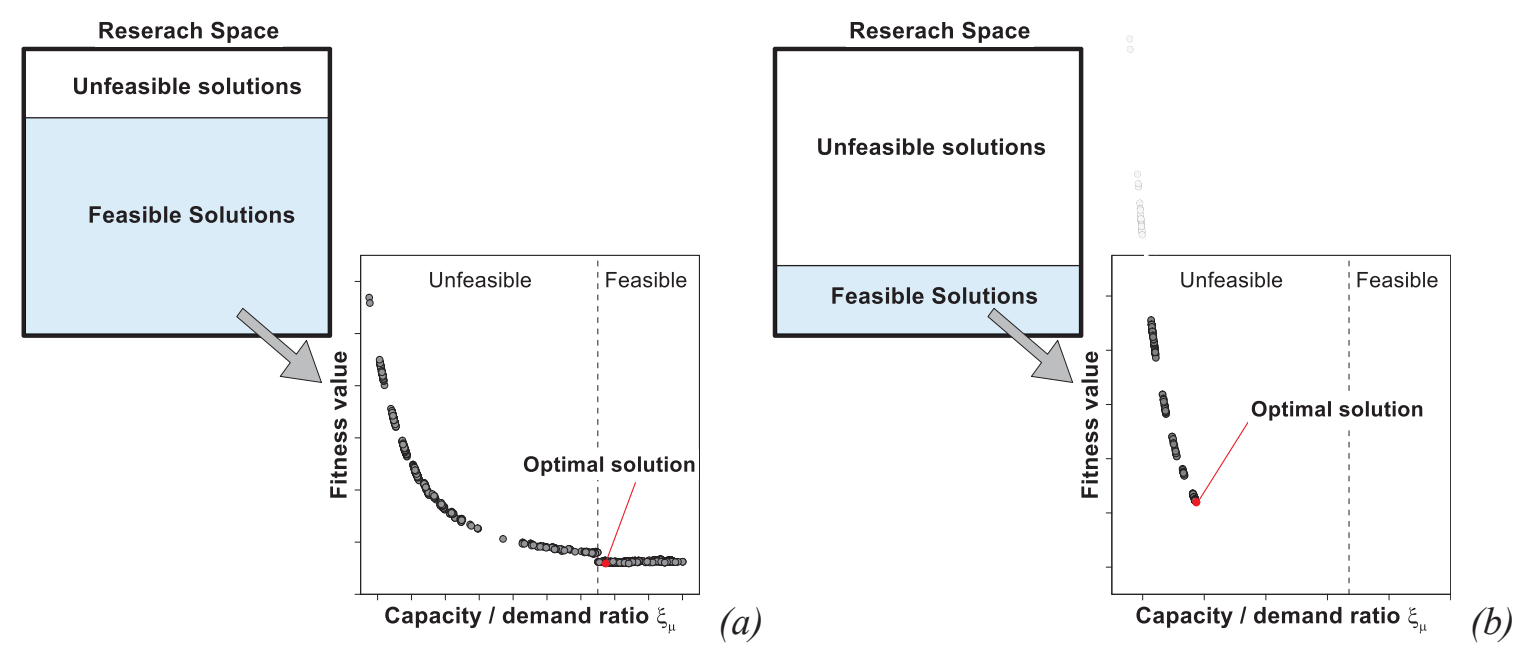

Figure 1: Possible optimization outcomes in case of: (a) design space with prevalence of feasible solutions; (b) design space with prevalence of unfeasible solutions. 


\subsection{Encoding of the design vector}

As mentioned in the previous sections, the design optimization variables are the position of the retrofitted columns and the battens spacing $\left(s_{b}\right)$, assuming that:

i) The angles are constituted by L-shaped steel profiles having fixed lateral length $\left(l_{a}\right)$ and thickness $\left(t_{a}\right)$ for all the retrofitted columns.

ii) The battens are constituted by rectangular plates having fixed thickness $\left(t_{b}\right)$ and width $\left(w_{b}\right)$ for all the retrofitted columns.

iii) Battens spacing is the same for all the retrofitted columns.

iv) The design space can be restricted to a reduced number of columns (e.g. those belonging to the lower storeys).

A schematic representation of the design variables is illustrated in Fig. 2.
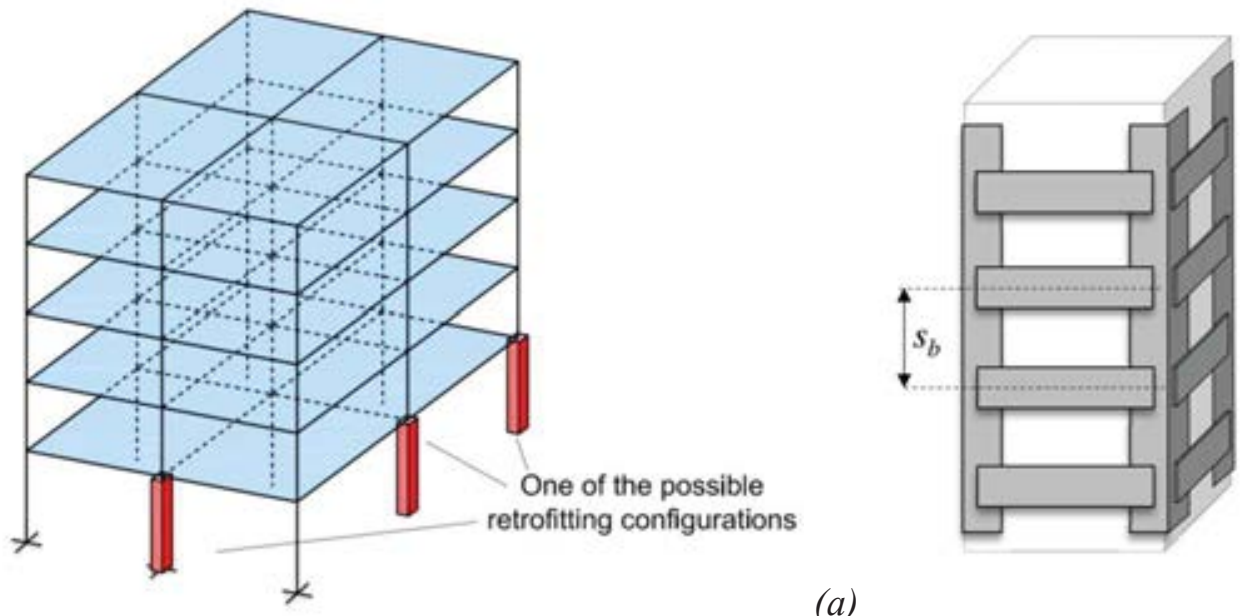

(a)

(b)

Figure 2: Representation of the optimization variables: (a) Generic column retrofitting configuration for an $\mathrm{RC}$ structure; (b) Typical retrofitting arrangement for a column with generic batten spacing $\left(s_{b}\right)$.

The design vector collecting the design variable is formalized as follows:

$$
\boldsymbol{b}=\left(\begin{array}{c}
s_{b} \\
\boldsymbol{p}
\end{array}\right)
$$

where $s_{b}$ is a natural discrete number that represent the battens spacing (Fig. 4b), belonging to the interval:

$$
s_{b} \in S=\left\lfloor s_{b, \text { min }} \quad s_{b, \max }\right\rfloor
$$

where $s_{b, \min }$ and $s_{b, \max }$ are the respectively the minimum and maximum battens spacing allowed. The element $\boldsymbol{p}$ is the vector so defined:

$$
\boldsymbol{p}=\left[\begin{array}{llll}
\ldots & \ldots & c_{i j} & \cdots
\end{array}\right]^{\mathrm{T}}
$$

in which the generic element $c_{i j}$, is a binary number assuming the value 1 if a column is retrofitted and 0 if not. The subscript $i$ denotes the position of a column in plan and $i$ the storey. In this way, each individual (namely a model) generated by the GA is univocally defined by the $b$ vector, which characterizes position and battens spacing of the retrofitted columns. 


\subsection{Definition of objective function and penalty function}

The objective function evaluates retrofitting cost intended as the material cost and the manpower cost to realize columns steel jacketing $\left(C_{S J}\right)$ and necessary works for demolition and reconstruction of plasters and masonry $\left(C_{M}\right)$. The general expression of the objective function is therefore:

$$
C=C_{M}+C_{S J}
$$

The cost $C_{M}$ is estimated considering a fixed amount $\left(c_{m}\right)$ of $2000 €$ per column. Assuming $n_{c}$ as the number of retrofitted columns and all the potentially retrofitted columns have the same cross-section dimension, one obtains:

$$
\left\{\begin{array}{l}
C_{M}=n_{c} \cdot c_{m} \\
C_{S J}=n_{c} W_{s} c_{s}
\end{array}\right.
$$

where $W_{s, i}$ is the total weight of steel used to arrange a steel jacketing cage, $c_{s}$ is the manpower and material cost per unit weight, which is estimated as $4.5 € / \mathrm{kg}$ and $W_{s}$ is the weight of each steel jacketing cage. The latter can be computed as:

$$
W_{s}=\gamma_{s} \cdot\left(V_{A}+V_{B}\right)
$$

in which $\gamma_{s}$ is the specific weight of steel $\left(78.5 \mathrm{kN} / \mathrm{m}^{3}\right), V_{A}$ is the total weight of the steel angles applied at the corners of a columns and $V_{B}$ is the total volume of the battens belonging to a cage (on the assumption of column of square cross section), that are:

$$
\left\{\begin{array}{l}
V_{A}=8 \cdot l_{a} \cdot t_{a} \cdot l_{c} \\
V_{B}=2 \cdot t_{b} \cdot l_{b} \cdot\left((b+h)-2 \cdot l_{a}\right) \cdot\left(\frac{l_{c}}{s_{b}}\right)
\end{array}\right.
$$

where $l_{a}, t_{a}$ are the width and the thickness of an angle, $l_{b}, t_{b}$ are the width and the thickness of the batten, $b, h$ are the dimension of the cross section of the column and $l_{c}$ is the length of a column.

The feasibility of a solution is known by the evaluation of the capacity/demand ratio $\left(\xi_{\mu}\right)$. To effectively manage unfeasible cases a dynamic penalty approach is developed by summing to the objective function $(C)$ above defined the penalty function $(\Pi)$ into the new objective function $(F)$ so defined:

$$
F=C+\Pi
$$

where $\Pi$ is defined as:

$$
\Pi=\left\{\begin{array}{cc}
0 & \text { if } \xi_{\mu} \geq 1 \\
C_{\max } \cdot\left(\frac{1}{\xi_{\mu}}\right)^{3} & \text { if } \xi_{\mu}<1
\end{array}\right.
$$

in which $C_{\max }$ is the maximum possible retrofitting cost evaluated by considering retrofitting all the columns included in the design space with the minimum battens spacing. In this way, if 
a solution is not feasible, the current cost is fictitiously increased by $C_{\max }$ multiplied by the factor $\left(1 / \xi_{\mu}^{3}\right)$ which takes into account the distance of the current solution from the feasibility condition $\left(\xi_{\mu}=1\right)$.

\section{DEFINITION OF THE GENETIC OPERATORS}

\subsection{Population generator and elitism}

The control of the population in terms of the selection of individuals is essential to the optimization effectiveness. As defined in Eq. 1, the genotype of each individual is a vector composed of one natural number representing the battens spacing $\mathrm{s}_{\mathrm{b}}$, and a sub-vector (p) collecting a number of binary variables which represent the retrofitted columns. In the selection phase, the parameter $\mathrm{Sb}$ is randomly selected by the $\mathrm{S}$ interval, which includes all possible spacing values as a multiple of a fixed minimum spacing variation $\Delta s b$.

As mentioned in previous sections, and depicted in Fig. 1, in case of structures having shear-related deficiencies, the number of unfeasible solutions belonging to the design space can be relevant. In order to avoid algorithm stall into unfeasible design subspace, the population generator operator has been modified by introducing two subspaces in the definition of initial population (Fig. 3). The first subspace ( $p_{\text {rand }}$ space) collects randomly created individual. The second subspace ( $p_{P r}$ space) is defined by a specified percentage $\left(p_{P r}\right)$ of individuals having an assigned probability of retrofitting $\left(P_{r}\right)$. The percentage of randomly selected individuals $\left(p_{\text {rand }}\right)$ is the complement to $100 \%$. The probability $P_{r}$ is typically high (e.g. $90 \%$ ), this means that an individual included the $p_{P r}$ space is an individual with a high number of retrofitted column. The introduction of the $p_{P r}$ space within the initial population increases from the beginning the number of feasible solutions. This allows reducing population dimension and increasing the exploration efficiency of the algorithm.

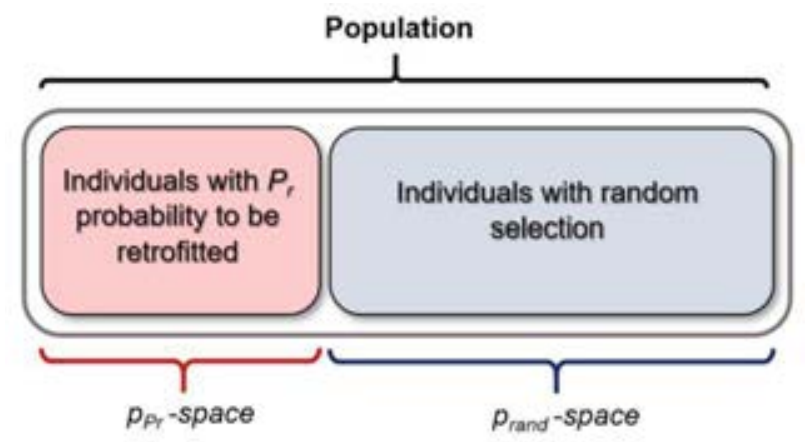

Figure 3: Definition of the population (population generator).

To further improve the algorithm performance, the elitism function is used. This genetic operator involves copying a small number of the fittest candidates, unchanged, into the next generation. In fact, the fittest individuals of a population can be lost during the crossover operations of consecutive generation analysis. Then, the use of the elitism function allows not losing good genetic heritage and consequently speeds up convergence. 


\subsection{Mutation and crossover}

The crossover operator is employed to improve the genes of the individuals at the end of each generation. This is done by mixing chromosomes from parent better individuals. A uniform scatter crossover function is used in the proposed framework. The operating principle provides randomly selection of pairs of parent individuals from the previous generation. Their genomes are mixed with the generation of a random binary string of the same dimension of the parents. Base on the binary value ( 0 or 1 ) associated with each position, the gene is transferred to the child from the parent 1 or 2 (Fig. 4a).

The crossover function here used has a standard form, while modifications are made in the mutation operator. Mutation is used to bring about random changes in the population.

The standard MATLAB ${ }^{\circledR}$ mutation operator cannot handle heterogeneous vectors (e.g. vectors made of natural numbers and binaries as the vector $\boldsymbol{b}$ ), and this made necessary the definition of a new mutation function. The latter works by fixing first a suitable mutation ratio $\left(P_{m}\right)$. Then a real number $u(u \in[0,1] \subseteq \Re)$ is randomly selected for each gene. If $u \geq P_{m}$ the gene is maintained unchanged, otherwise if $u<P_{m}$ the gene is mutated. For the Boolean variables included in the design vector, the mutation of a gene is simply a switch from 0 to 1 or vice-versa. For the natural variables (the battens spacing $s_{b}$ ) the same procedure is applied, but in the cases in which a gene has to change $\left(u<P_{m}\right)$ a further random number $v(v \in[0,1] \subseteq \mathfrak{R})$ is chosen in order to decide if mutation will increase or decrease the battens spacing.

The new random temporary parameter $v$ leads the mutation toward an increase or decrease of $s_{b}$ if $v<0.5$ or $v \geq 0.5$ respectively. Increases and decreases of $s_{b}$ have the magnitude of the minimum spacing variation $\left(\Delta s_{b}\right)$. A flow-chart example of the proposed mutation function is illustrated in Fig. $\mathbf{4 b}$.

The application to the current case, in which a limited dimension of the population is used, require to increase the mutation to values which are larger than $1 \%$. The relatively high value of mutation ratio helps in avoiding the stall of the analysis into local optimal solution.

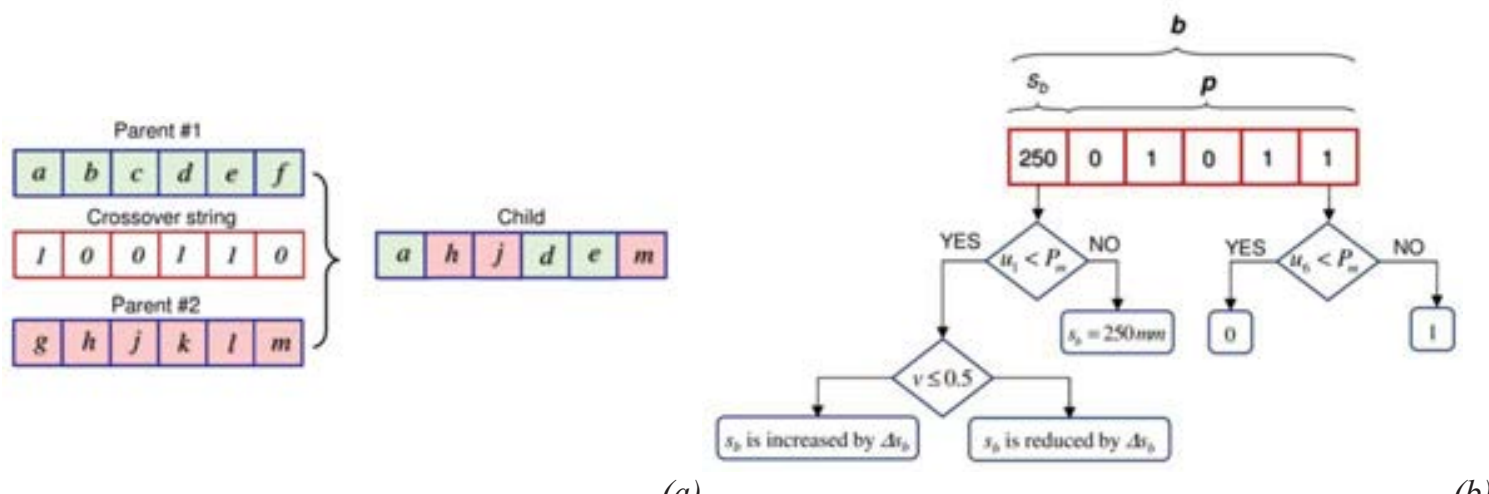

(a)

(b)

Figure 4: Example flow-charts of the: (a) uniform scatter crossover function; (b) proposed mutation function.

\section{REFERENCE STRUCTURAL MODEL}

The proposed optimization framework can work with any finite element program handling nonlinear static analysis. Tests and application presented in the current study are carried out using the OpenSees software platform and the structural modelling assumptions below described. 


\subsection{Modelling of RC elements with and without steel-jacketing}

Frame elements are modelled adopting distributed plasticity force-based elements with five Gauss-Lobatto integration points available in OpenSees (Fig. 5). Fiber-section elements are modelled using a Concrete02 uniaxial material model for the cross-section fibers. It is assumed that the effect of confinement is extended to the whole cross-section (Fig. 5) both for the cases of columns with and without steel jacketing reinforcement. This simplified assumption allows a formal consistency with the confinement model in the case of concrete confined by stirrups and steel jacketing (Campione et al. 2017 [12]) which provides uniform confinement over the cross-section. In order to simulate the crushing of the cross-section fibers, Concrete 02 material is combined with MinMax material. For the current case, it is assumed that crushing of fibers occurs in correspondence of the compressive strain $\left(\varepsilon_{c r}\right)$ attained at a $30 \%$ reduction of the peak strength (Fig. 8).

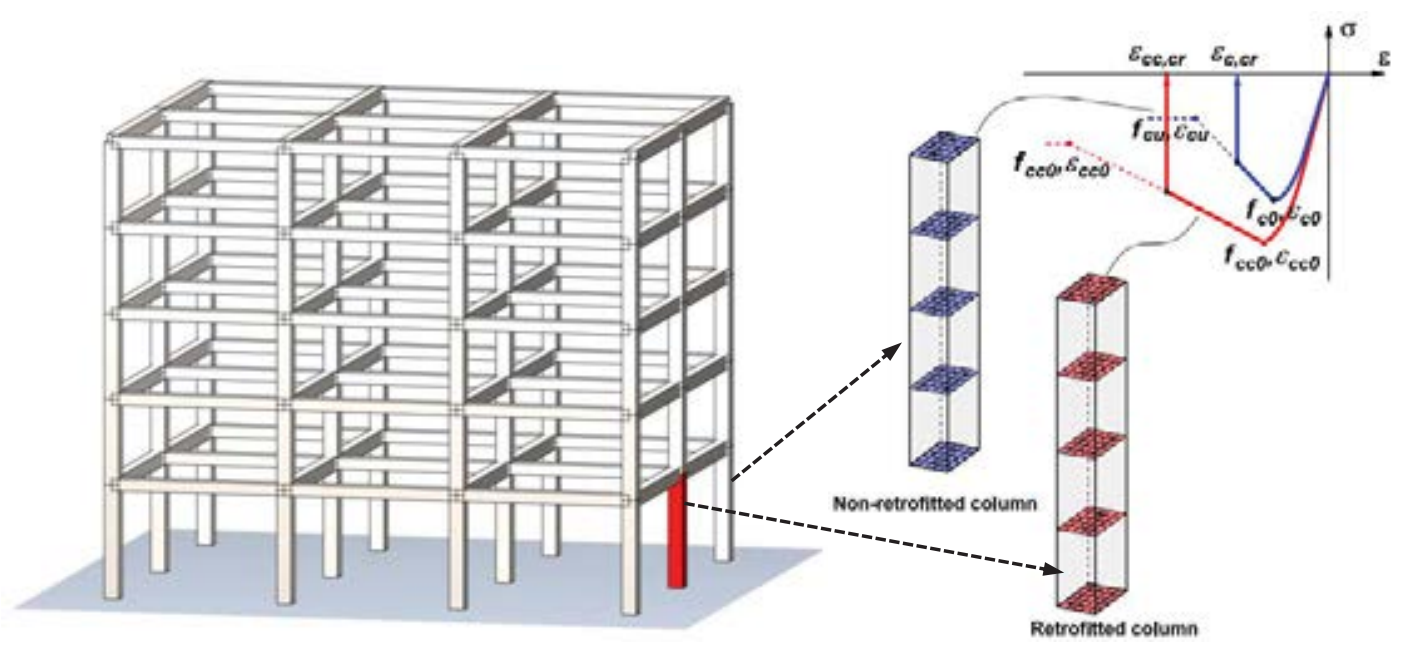

Figure 5: Definition of the frame fiber-section elements with and without steel-jacketing reinforcement.

Confined concrete for RC elements confined only by stirrups will be characterized by parameters $f_{c 0}, f_{c u}, \varepsilon_{c 0}, \varepsilon_{c u}$ (Fig. 5), while these parameters are changed into $f_{c c 0}, f_{c c u}, \varepsilon_{c c 0}, \varepsilon_{c c u}$ for $\mathrm{RC}$ elements confined by stirrups and steel jacketing (Fig. 5). Confined concrete parameters for the RC elements confined only by stirrups are evaluated using the stress-strain model by Razvi and Saatcioglu 1992 [13]. As for the columns with steel jacketing retrofitting, confined concrete parameters are obtained using the procedure already presented by Di Trapani et al. 2020 [9], which is based on the model by Campione et al. 2017 [12].

Steel rebars are modelled using the Steel02 (Giuffrè-Menegotto-Pinto) material model (elasto-plastic with linear strain hardening). Finally, rigid diaphragm behaviour is imposed at the floor nodes.

\subsection{Modelling of masonry infills}

Masonry infills (if any) are modelled as equivalent diagonal struts resisting only in compression. The equivalent strut model by Di Trapani et al. 2018 [14] is used for the fibersection struts. The model provides a concrete-type compression-only stress-strain relationship defined by the four parameters, peak stress $\left(f_{m d 0}\right)$, ultimate stress $\left(f_{m d u}\right)$, peak strain $\left(\varepsilon_{m d 0}\right)$ and ultimate strain $\left(\varepsilon_{m d u}\right)$ obtained by empirical equations. The infill is supposed to collapse in correspondence of the axial strain $\varepsilon_{m d c}=2 \cdot \varepsilon_{m d u}$. 


\section{STRUCTURAL ANALYSIS AND POSTPROCESSING}

\subsection{Pushover curve post-processing for feasibility assessment}

The feasibility of each solution is assessment by a pushover analysis of the individual. Pushover analysis is carried out in the framework of the N2 method (Fajfar 2000 [11]), also provided by Eurocode 8 [15]. The feasibility of each solution is assessed by evaluating the ductility capacity / demand ratios defined by:

$$
\xi_{\mu}=\frac{\mu_{c}}{\mu_{d}}
$$

Where the ductility capacity $\left(\mu_{c}\right)$ is obtained as the ratio between the ultimate displacement capacity $\left(d_{u}^{*}\right)$ and the yielding displacement $\left(d_{y}^{*}\right)$ of the single degree of freedom bilinear equivalent curve (Fig. 6), while the ductility demand $\left(\mu_{d}\right)$ of an inelastic SDOF system is evaluated as:

$$
\begin{cases}\mu_{d}=\left(q^{*}-1\right) \frac{T_{c}}{T^{*}}+1 & \text { if } T^{*} \leq T_{c} \\ \mu_{d}=q^{*} & \text { if } T^{*}>T_{c}\end{cases}
$$

where $T^{*}$ is the period of the equivalent SDOF system having mass $m^{*}$, and stiffness $k^{*}$ and reduction factor $q^{*}$ evaluated as:

$$
T^{*}=2 \pi \sqrt{\frac{m^{*}}{k^{*}}} ; k^{*}=\frac{F_{y}^{*}}{d_{y}^{*}} ; q^{*}=\frac{S_{a e}\left(T^{*}\right) m^{*}}{F_{y}^{*}}
$$

The coefficient $\xi_{\mu}$ is the final output of the processing of pushover curves and is used as a discriminating factor in the optimization process in order to establish the feasibility of each a single individual $\left(\xi_{\mu} \geq 1\right)$.
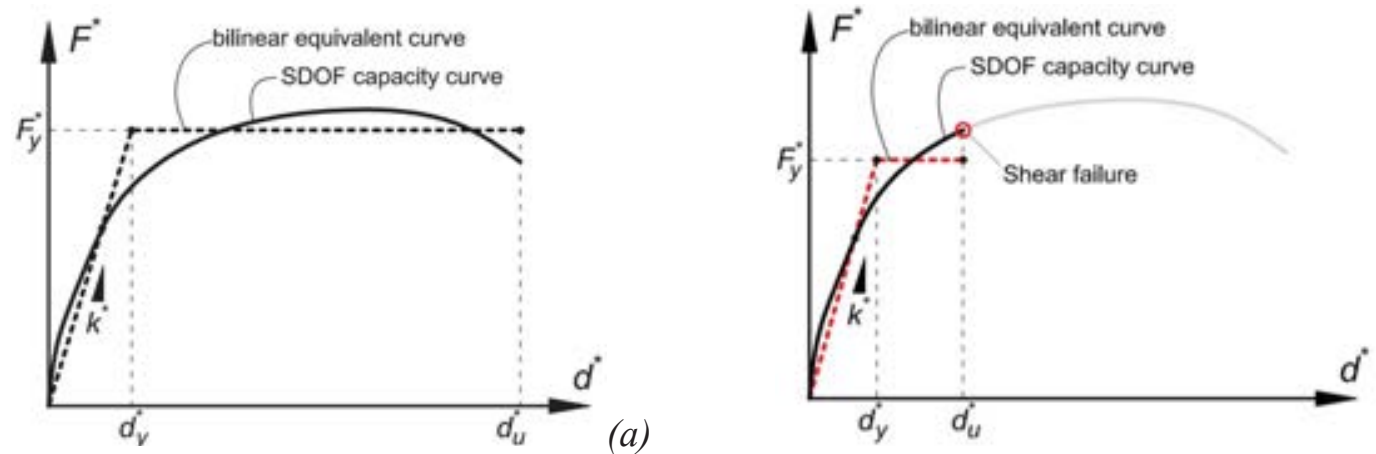

Figure 6: Typical equivalent SDOF capacity curve and bilinear equivalent curve for: (a) shear-resistant structure;

(b) shear-critical structure.

\subsection{Shear verification of RC elements with and without steel-jacketing}

Shear verification of columns is carried out in the post-processing phase in terms of strength. The ultimate displacement capacity of assumed for the SDOF system is the one associated with the first shear failure of a column. Therefore, if shear failure of a column occurs, the capacity curve is cut in correspondence of that event (Fig. 6b). Shear verifications are carried out according to the model by Biskinis et al. 2004 [16], also included in Eurocode 8 [15] and in the Italian Technical Code [17] for the evaluation of shear strength of element 
subjected to seismic loads. Still according to Italian Technical Code [17], the contribution of the steel-jacketing to the shear strength is evaluated.

\subsection{Additional shear demand caused by infill-frame interaction}

Masonry infills induce significant increase of shear in adjacent columns. In case of single concentric strut, the additional shear demand due to infills $\left(V_{C, \text { inf }}\right)$ can be estimated as (Di Trapani and Malavisi 2019 [18]):

$$
V_{C, i n f}=P_{s t r} \cdot \cos \alpha-\mu \cdot P_{s t r} \cdot \sin \alpha
$$

where, referring to the Fig. 9, $P_{s t r}$ is the current value of the axial force acting on the equivalent strut, $\alpha$ is the angle of inclination of the strut with respect to horizontal direction, and $\mu$ the friction coefficient associated with the infill-mortar-frame interface and assumed as 0.7 in absence of more detailed evaluations. The total shear demand on a column of the frame adjacent to and infill $\left(V_{D}\right)$ will be the evaluated as the sum of shear force currently acting on the column $\left(V_{C, f r}\right)$ and the additional shear demand $\left(V_{C, \text { inf }}\right)$ so that:

$$
V_{D}=V_{C, f r}+V_{C, \text { inf }}
$$

\section{TEST OF THE PROPOSED FRAMEWORK}

As illustrated in previous sections, modified genetic operators have been introduced in the optimization framework. Their effectiveness is here tested in comparison with the standard ones, also providing some remarks on the most suitable calibration of parameters. The tests are carried out on a reference reinforced concrete frame case study structure having column with shear deficiencies in a high seismic hazard zone.

\subsection{Details of the reference structure}

The case study building consists of a five-storey reinforced concrete structure designed to resist only gravity loads. The building is supposed being located in Cosenza (Italy), soil type C. The reference nominal life $\left(V_{N}\right)$ is of 100 years. The resulting return period is $T_{R}=975$ years. The structure (Fig. 7) has double symmetry in plan and is regular in elevation. Modelling assumptions are those illustrated in Section 4. Reinforced concrete elements are supposed to be made of concrete having average unconfined strength $f_{c 0}=20 \mathrm{MPa}$ and steel rebars with nominal average yielding strength $f_{y}=455 \mathrm{MPa}$. Reinforcement details of beams and columns are shown in Fig. 12b and Table 1.

\begin{tabular}{cccc}
\hline $\begin{array}{c}\text { RC } \\
\text { members }\end{array}$ & $\boldsymbol{b} \times \boldsymbol{h}(\mathrm{mm})$ & $\begin{array}{c}\text { Longitudinal rein- } \\
\text { forcement }\end{array}$ & $\begin{array}{c}\text { Transverse re- } \\
\text { inforcement }\end{array}$ \\
\hline Beams & $400 \times 500$ & $4+4 \phi 18$ & $\phi 6 / 200 \mathrm{~mm}$ \\
Columns & $500 \times 500$ & $12 \phi 18$ & $\phi 6 / 200 \mathrm{~mm}$ \\
\hline
\end{tabular}

Table 1: Reinforcement details of beams and columns. 


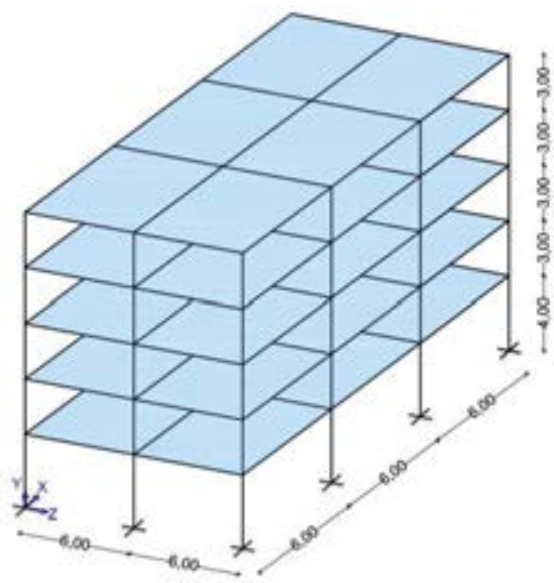

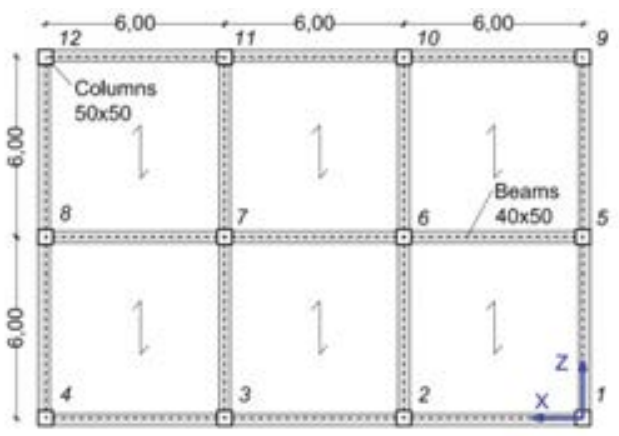

(a)

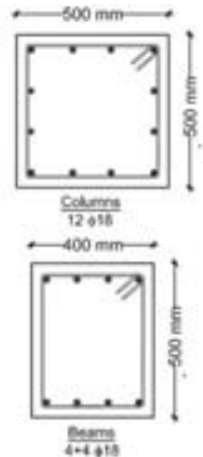

(b)

Figure 7: Geometrical dimensions of the case study structure: (a) 3D frame view; (b) dimensions in plan.

Vertical loads are modelled as point loads applied to the top node of each column as function of the respective tributary areas in plan. Pushover analyses are carried out by considering only a uniform profile for lateral loads acting along the softer direction of the structure.

A regards steel-jacketing retrofitting, it is supposed that angles and battens are made of steel having nominal yielding strength $f_{y b}=275 \mathrm{MPa}$ and the same dimension for angles and battens (Table 2), while the battens spacing $\left(s_{b}\right)$ range of optimization is $150-400 \mathrm{~mm}$.

\begin{tabular}{cc|ccc}
\hline \multicolumn{2}{c|}{ Angles } & \multicolumn{3}{c}{ Battens } \\
\hline $\begin{array}{c}\text { Lateral length } \boldsymbol{l}_{\boldsymbol{a}} \\
(\mathrm{mm})\end{array}$ & $\begin{array}{c}\text { Thickness } \\
\boldsymbol{W a}_{\boldsymbol{a}}(\mathrm{mm})\end{array}$ & $\begin{array}{c}\text { Width } \\
\boldsymbol{w}_{\boldsymbol{b}}(\mathrm{mm})\end{array}$ & $\begin{array}{c}\text { Thickness } \\
\boldsymbol{t}_{\boldsymbol{b}}(\mathrm{mm})\end{array}$ & $\begin{array}{c}\text { Spacing } \\
\boldsymbol{S} \boldsymbol{b}(\mathrm{mm})\end{array}$ \\
\hline Columns & 5 & 50 & 5 & $150-400$ \\
\hline
\end{tabular}

Table 2: Steel-jacketing arrangement details.

Moreover, to reduce the computational effort the following restriction have been applied to the design space:

i) Retrofitted columns can be only located within the first the second floor.

ii) Battens spacing optimization can vary with a minimum step size $\Delta s_{b}$ of $50 \mathrm{~mm}$

\subsection{Case study structural configurations description}

An application of the proposed framework is carried out for a case study structure supposing two different configurations of the infills. The reference reinforced concrete frame structure is the same as the one described in the previous section. Infills are supposed made clay hollow masonry having thickness $t=250 \mathrm{~mm}$, elastic modulus $E_{m}=6400 \mathrm{MPa}$ compressive strength $f_{m}=8.6 \mathrm{MPa}$ and shear strength $f_{v m}=1.07 \mathrm{MPa}$. Equivalent strut properties defined according to the model by Di Trapani et al. 2018 [14] are reported in Table 3.

\begin{tabular}{cccccc}
\hline $\begin{array}{c}t \\
(\mathrm{~mm})\end{array}$ & $\begin{array}{c}w \\
(\mathrm{~mm})\end{array}$ & $\begin{array}{c}f_{m d 0} \\
(\mathrm{MPa})\end{array}$ & $\begin{array}{c}f_{m d 0} \\
(\mathrm{MPa})\end{array}$ & $\begin{array}{c}\varepsilon_{m d 0} \\
(-)\end{array}$ & $\begin{array}{c}\varepsilon_{m d u} \\
(-)\end{array}$ \\
\hline 250 & 1053 & 1.88 & 0.86 & 0.010 & 0.073 \\
\hline
\end{tabular}

Table 3: Geometric and mechanical details of the equivalent struts. 
In the first infilled frame configuration (IFC-1), infills are located on the side frames with symmetric arrangement (Fig. 8a). In this configuration, infills are not provided on the ground floor. In the second configuration (IFC-2), infills are provided only in one of the external side frames and extended to the ground floor (Fig. 8b). The reason for the choice of these two infills configurations is related to the fact that they tend to induce a significantly different seismic demand to structures in terms of shear and ductility. Furthermore, the optimization of the two structures is carried out supposing the RC frame columns being shear-critical (SC) or shear-resistant (SR). In the first case, shear reinforcement of columns is supposed to be as described in Table 1. In the second case, columns are supposed to have adequate shear resistance to carry seismic loads. This further test allows examining the general efficacy of the proposed algorithm to work with both the typologies of structures.

Moreover, to reduce the computational burden, the design space of retrofitted columns is limited to the first two floors ( 24 columns), where the maximum seismic demand is expected in terms of shear and ductility. Optimization tests are carried out considering a pushover analysis with a uniform distribution of lateral forces along $z$ direction.

The adopted settings for the GA optimization framework are summarized in Table 4.
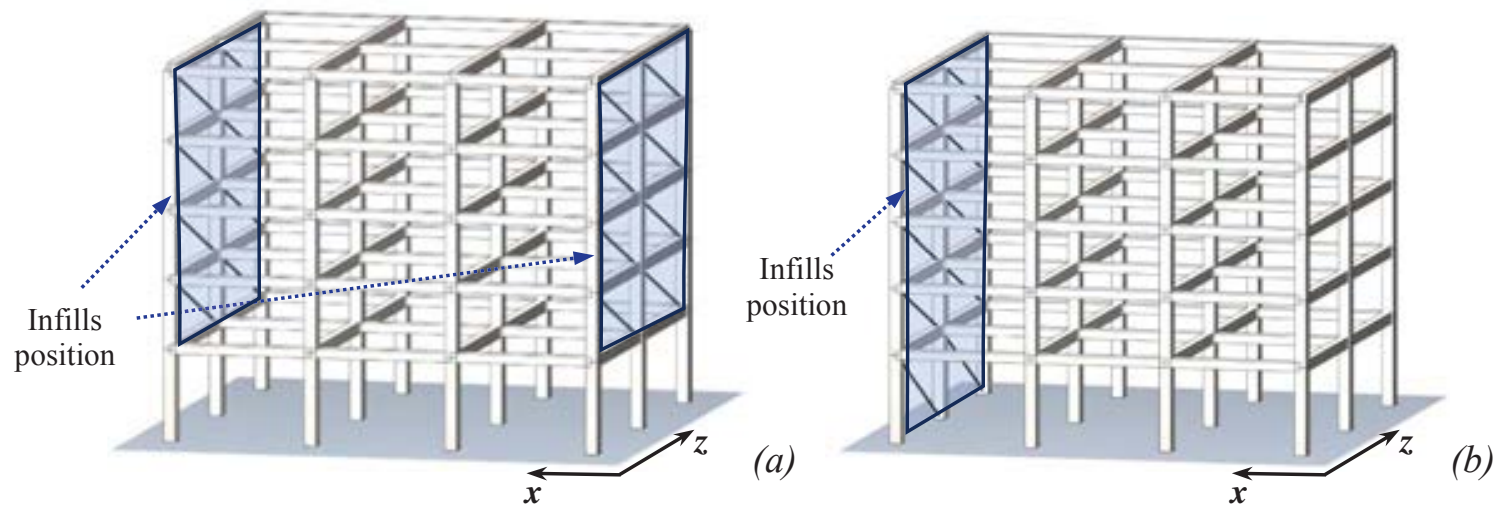

Figure 8: Case study structures: (a) IFC 1: symmetric positioning of infills with pilotis storey; (b) IFC2: asymmetric positioning of infills.

\begin{tabular}{cccccc}
\hline $\begin{array}{c}\text { Dimension of the } \\
\text { design vector } \\
\boldsymbol{d i m}(\boldsymbol{b})\end{array}$ & $\begin{array}{c}\text { Population } \\
\text { size } \\
\boldsymbol{P}\end{array}$ & $\begin{array}{c}\text { Dimension of } \\
\text { the } p_{P r} \text { space } \\
\boldsymbol{p} \boldsymbol{P r}\end{array}$ & $\begin{array}{c}\text { Prob. of retrofitting of an } \\
\text { element in the } p_{P r} \text { space } \\
\boldsymbol{P}_{\boldsymbol{r}}\end{array}$ & $\begin{array}{c}\text { Probability of } \\
\text { mutation } \\
\boldsymbol{P}_{\boldsymbol{m}}\end{array}$ & $\begin{array}{c}\text { No. of indiv. subject } \\
\text { to Elitism per gen. } \\
\boldsymbol{E}\end{array}$ \\
\hline 25 & 80 & $50 \%$ & $90 \%$ & 10 & $5 \%$ \\
\hline
\end{tabular}

Table 4: GA framework settings used for the case studies.

\subsection{Optimization results and discussion}

As previously mentioned, four optimization tests have been carried out with the aim of assessing first the responsiveness of the proposed framework in finding optimal retrofitting solution under different potential damage scenarios (IFC-1 and IFC-2 configurations). Secondly, the general validity of the framework, and in particular of the modified genetic operators, has been tested by considering both shear-critical (SC) and shear resistant (SR) configurations for the columns. This allows understanding the algorithm performance as a function of the variety of the population. 

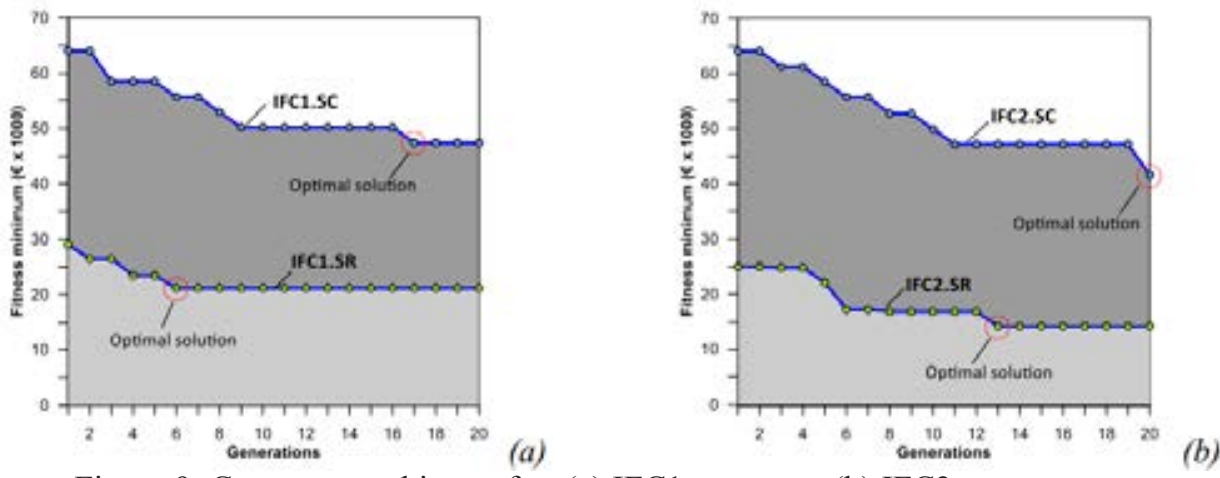

Figure 9: Convergence history for: (a) IFC1 structure; (b) IFC2 structure.

The convergence histories of the tests are depicted in Figs. 9. As it can be observed, the proposed framework is able to pinpoint an optimal solution for each examined cases efficiently. The performances of the optimal retrofitting configurations in terms of capacity curves are displayed in Figs. 10.

The consistency of the optimal retrofitting arrangements with the expected structural deficiencies is very clear from Figs. 11, showing the structural deformed shapes under $z+$ pushover loads and depicting in red the retrofitted columns. In fact, for both IFC-1 and IFC-2 shear resistant structures, retrofitting was provided for central columns that have reduced ductility because of the significant axial force, and leeward columns subjected to axial force increases because of the base moment. The significant amount of retrofitted columns for the IFC-1.SR configuration is related to the more severe damage mechanism (soft storey) induced by lateral loads. For what concerns shear-critical configurations IFC-1.SC and IFC2.SC, more retrofitted columns were found. The shear deficiency of columns and the associated retrofitting demand is more evident observing Figs. 11b, 11d. This highlights that the additional shear demand due to the pushing action of infills plays a relevant role. In fact, retrofitting was requested to every leeward column adjected to the equivalent struts.

For all the retrofitting configurations low battens spacing was found $\left(s_{b}=150 \div 200 \mathrm{~mm}\right)$. This can be justified considering that fixed costs influenced more than steel cage related costs. Therefore, the framework tends to prefer solutions providing the minimum possible number of columns even with reducing the spacing of battens.
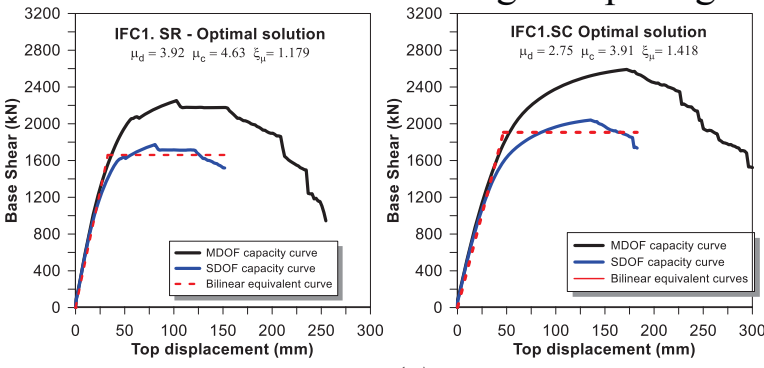

(a)

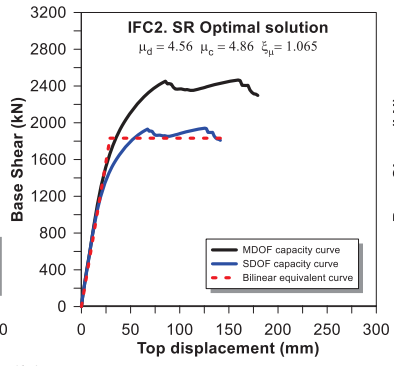

(b)

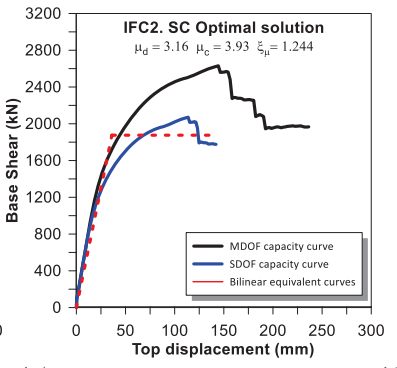

(c) (d)

Figure 10: Optimal solutions capacity curves for: (a) IFC1.SR; (b) IFC1.SC; (c) IFC2.SR; (d) IFC2.SC

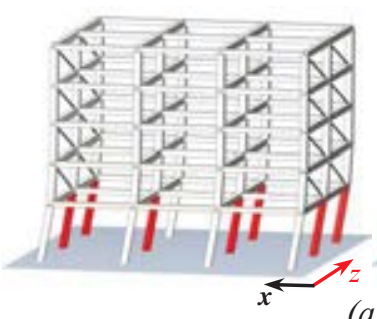

(a)

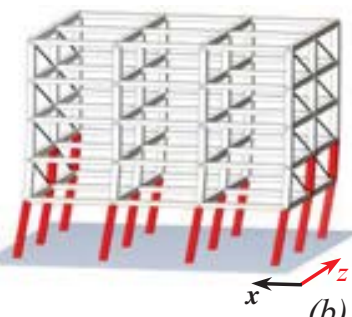

(b)

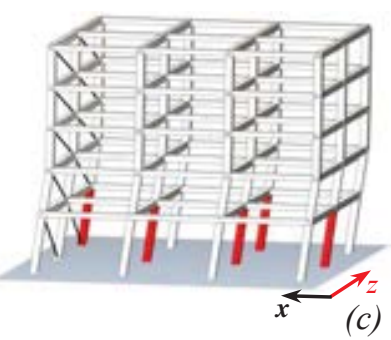

(c)

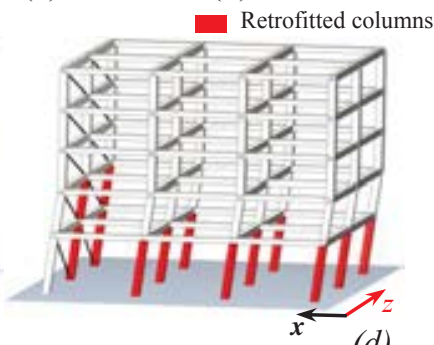

(d)

Figure 11: Optimal retrofitting arrangements for: (a) IFC1.SR; (b) IFC1.SC; (c) IFC2.SR; (d) IFC2.SC 
Results of the optimization test in terms of cost, performance and arrangement are summarized in Table 5. Based on the previously discussed results the proposed framework has demonstrated to be sufficiently robust against the heterogeneity of the populations.

The advantages in terms of economical cost savings can certainly justify the application of a retrofitting optimization framework in the current practice. Of course, this is even more true for larger reinforced concrete frames structures, where retrofitting and downtime costs become a crucial issue.

\begin{tabular}{ccccccc}
\hline $\begin{array}{c}\text { Structural } \\
\text { configuration }\end{array}$ & $\begin{array}{c}\boldsymbol{S}_{\boldsymbol{b}} \\
(\mathrm{mm})\end{array}$ & $\begin{array}{c}\boldsymbol{n}_{\boldsymbol{c}} \\
(-)\end{array}$ & $\begin{array}{c}\boldsymbol{C} \\
(€)\end{array}$ & $\begin{array}{c}\boldsymbol{\mu}_{\boldsymbol{d}} \\
(-)\end{array}$ & $\begin{array}{c}\boldsymbol{\mu}_{\boldsymbol{c}} \\
(-)\end{array}$ & $\begin{array}{c}\boldsymbol{\xi}_{\boldsymbol{\mu}} \\
(-)\end{array}$ \\
\hline IFC1.SR & 150 & 7 & 21171 & 3.92 & 4.63 & 1.179 \\
IFC1.SC & 150 & 16 & 47402 & 2.75 & 3.90 & 1.419 \\
IFC2.SR & 200 & 5 & 14239 & 4.56 & 4.86 & 1.065 \\
IFC2.SC & 150 & 13 & 38823 & 3.15 & 3.93 & 1.244 \\
\hline
\end{tabular}

Table 5: Results of the optimization.

\section{CONCLUSIONS}

The paper presented a new genetic algorithm-based framework aimed at the optimization of steel-jacketing retrofitting interventions costs in reinforced concrete frame structures subjected to seismic loads. The proposed optimization framework can effectively handle both in the cases of shear resistance and flexural ductility lacks, providing as output the retrofitted columns' position and the amount of reinforcement associated with the minimum cost.

The development of the optimization framework was based on the MATLAB ${ }^{\circ}$ GA tool, addressing special effort in revising the standard genetic operators (population generator, elitism, and mutation) to effectively handle retrofitting optimization of RC frame structures in the cases of lacks in ductility, shear or combined shear and ductility.

The proposed framework has been tested with a reference structure with different infills configurations and assuming the columns to be shear-critical or shear-resistant. Results have shown that the optimization algorithm is sufficiently general and robust both for the cases of shear-deficient or ductility-deficient structures. Economic and downtime gains are not clearly evident for structures with reduced size (as the ones examined in the paper); however substantial savings can be expected for larger RC structures with a noticeable number of columns.

\section{REFERENCES}

[1] L.P. Chaves, J. Cunha, Design of carbon fiber reinforcement of concrete slabs using topology optimization. Construction and Building Materials, 73, 688-98, 2014.

[2] C. Chisari, C. Bedon, Multi-Objective Optimization of FRP Jackets for Improving the Seismic Response of Reinforced Concrete Frames. American Journal of Engineering and Applied Sciences, 9(3), 669-679, 2016.

[3] H. Seo, J. Kim, M. Kwon, Optimal seismic retrofitted RC column distribution for an existing school building. Engineering Structures, 168, 399-404, 2018.

[4] N. Pollini, O. Lavan, O. Amir, Minimum-cost optimization of nonlinear fluid viscous dampers and their supporting members for seismic retrofitting. Earthquake Engineering \& Structural Dynamics, 46, 1941-1961, 2017.

[5] F. Braga, R. Gigliotti, R. Laguardia, Intervention cost optimization of bracing systems with multiperformance criteria. Engineering Structures, 182, 185-197, 2019. 
[6] O. Lavan, G.F. Dargush, Multi-objective evolutionary seismic design with passive energy dissipation systems. Journal of Earthquake Engineering, 13(6), 758-790, 2009.

[7] R. Falcone, F. Carrabs, R. Cerulli, C. Lima, E. Martinelli, Seismic retrofitting of existing rc buildings: a rational selection procedure based on genetic algorithms. Structures, 22, 310-326, 2019.

[8] G.S. Papavasileiou, D.C. Charmpis, N.D. Lagaros, Optimized seismic retrofit of steelconcrete composite buildings. Engineering Structures, 213, 110573, 2020.

[9] F. Di Trapani, M. Malavisi, G.C. Marano, A.P. Sberna, R. Greco, Optimal seismic retrofitting of reinforced concrete buildings by steel-jacketing using a genetic algorithmbased framework. Engineering Structures, 219, 110864, 2020.

[10] F. McKenna, G.L. Fenves, M.H. Scott, Open system for earthquake engineering simulation. University of California Berkeley, 2000.

[11] P. Fajfar, A Nonlinear Analysis Method for Performance-Based Seismic Design. Earthquake Spectra 16(3), 573-592, 2000.

[12] G. Campione, L. Cavaleri, F. Di Trapani, M.F. Ferrotto, Frictional effects in structural behavior of no end-connected steel-jacketed RC columns: experimental results and new approaches to model numerical and analytical response. Journal of Structural Engineering, 143(8), 04017070, 2017.

[13] S.R. Razvi, M. Saatcioglu, Strength and Ductility of Confined Concrete. Journal of Structural Engineering, 125(3), 281-298, 1992.

[14] F. Di Trapani, G. Bertagnoli, M.F. Ferrotto, D. Gino, Empirical equations for the direct definition of stress-strain laws for fiber-section-based macro-modeling of infilled frames. Journal of Engineering Mechanics, 144(11), 04018101, 2018.

[15] Eurocode 8. Design of structures for earthquake resistance - Part 1: general rules, seismic actions and rules for buildings. European Committee for Standardization, 2004.

[16] D.E. Biskinis, G.K. Roupakias, M.N. Fardis, Degradation of shear strength of reinforced concrete members with inelastic cyclic displacements. Structural Journal, 101(6), 773-783, 2004.

[17] Norme tecniche per le costruzioni. Decreto ministeriale 17 gennaio 2018. Ministero delle infrastrutture e dei trasporti, 2018.

[18] F. Di Trapani, M. Malavisi, Seismic fragility assessment of infilled frames subject to mainshock/aftershock sequences using a double incremental dynamic analysis approach. Bulletin of Earthquake Engineering, 17(1), 211-235, 2019.

[19] F. Di Trapani, V. Bolis, F. Basone, M. Preti, Seismic reliability and loss assessment of RC frame structures with traditional and innovative masonry infills. Engineering Structures, 208, 110306, 2020.

[20] L. Cavaleri, F. Di Trapani, M.F. Ferrotto, A new hybrid procedure for the definition of seismic vulnerability in Mediterranean cross-border urban areas. Natural Hazards, 86(2), 517-541, 2017.

[21] L. Cavaleri, F. Di Trapani, M.F. Ferrotto, L. Davì, Stress-strain models for normal and high strength confined concrete: Test and comparison of literature models reliability in reproducing experimental results. Ingegneria Sismica, 34(3-4), 114-137, 2017. 